\title{
Studi Perencanaan Bangunan Ipal Di Desa Blang Beurandang, Kabupaten Aceh Barat
}

\author{
Meylis Safriani*1 ${ }^{1}$, Cut Suciatina Silvia ${ }^{2}$ \\ ${ }^{1,2}$ Jurusan Teknik Sipil Universitas Teuku Umar, Alue Penyareng, Meulaboh, Aceh Barat \\ e-mail: *1mey2_saza@yahoo.com, ${ }^{2}$ coetsilvia@gmail.com
}

\begin{abstract}
Iom Housing Blang Beurandang Village is a dense neighborhood where the population consists of 56 families with 160 people. Based on the preliminary survey, every household in IOM Housing already has a toilet. However, it does not yet have wastewater treatment in a septic tank. Based on these problems, it is necessary to plan the installation of communal waste treatment to improve the sanitation system in this village. Data collection in this study with primary data collection and secondary data. Primary data includes interviews and site surveys as location of IPAL planning (to obtain data on the characteristics of waste water in Blang Beurandang Village). Secondary data include population data, house number data, and topographic map of planning area. The design result obtained dimension of IPAL Building is planned to have length $11 \mathrm{~m}$ and width of building 3.25 meter. This building consists of several spaces including an inlet tub with dimensions of $1.15 \mathrm{~m}$ long and $3.25 \mathrm{~m}$ wide, tub settler with a length of $4.00 \mathrm{~m}$ and $3.25 \mathrm{~m}$ width, dividing tub with length of $0.80 \mathrm{~m}$ and width of 3, $25 \mathrm{~m}$, tub filter (tub media filter) with a length of $1 \mathrm{~m}$ and a width of $1 \mathrm{~m}$ of 12 pieces and outlet with a length of $1 \mathrm{~m}$ and width of $1 \mathrm{~m}$. In the filter basin is used biofilter in order to grow bacteria with anaerobic system. Biofilter is usually used which is fabrication. However, in the design of this WWTP biofilter used from the materials used plastic bottles are recycled in order to reduce waste and also to save the cost of development expenditure.
\end{abstract}

Keywords: waste, waste treatment, installation of communal waste treatment

\begin{abstract}
Abstrak
Perumahan Iom Desa Blang Beurandang merupakan lingkungan yang padat dimana jumlah penduduk terdiri dari 56 KK dengan jumlah 160 orang. Berdasarkan survei awal, di setiap rumah masyarakat di Perumahan Iom sudah memiliki WC. Namun, belum memiliki pengolahan air limbah pada tangki septiktank. Berdasarkan permasalahan tersebut, dibutuhkan perencanaan instalasi pengolahan limbah komunal untuk memperbaiki sistem sanitasi di desa ini. Pengumpulan data pada penelitian ini dengan pengumpulan data primer dan data sekunder. Data primer meliputi wawancara dan survei lokasi sebagai lokasi perencanaan IPAL (untuk mendapatkan data karakteristik air limbah Desa Blang Beurandang). Data sekunder meliputi data jumlah penduduk, data jumlah rumah, dan peta topografi wilayah perencanaan. Hasil desain diperoleh dimensi Bangunan IPAL direncanakan memiliki panjang $11 \mathrm{~m}$ dan lebar bangunan 3.25 meter. Bangunan ini tediri dari beberapa ruang di antaranya bak inlet dengan dimensi panjang $1.15 \mathrm{~m}$ danlebar $3.25 \mathrm{~m}$, bak settler (bak pengendap) dengan panjang 4,00 m dan lebar 3,25 m, bak pembagi dengan panjang 0,80 $\mathrm{m}$ dan lebar 3,25 m, bak filter (bak media filter) dengan panjang $1 \mathrm{~m}$ dan lebar $1 \mathrm{~m}$ sebanyak 12 buah dan bak keluar (outlet) dengan panjang $1 \mathrm{~m}$ dan lebar $1 \mathrm{~m}$. Pada bak filter digunakan biofilter dengan tujuan untuk menumbuhkan bakteri dengan sistem anaerob. Biofilter biasanya digunakan yang fabrikasi. Namun pada desain IPAL ini digunakan biofilter dari bahan botol plastik bekas yang didaur ulang dengan tujuan untuk mengurangi sampah dan juga untuk menghemat biaya pengeluaran pembangunan.
\end{abstract}

Kata Kunci: limbah, pengolahan limbah, IPAL 


\section{PENDAHULUAN}

Komponen penting dalam menunjang setiap aktivitas manusia adalah air. Air sangat dibutuhkan oleh manusia untuk proses metabolisme tubuh, juga untuk melakukan berbagai proses dalam kegiatannya. Salah satunya adalah kegiatan dalam proses rumah tangga dan industri. Semakin bertambahnya jumlah perumahan dan perkampungan yang mendiami satu area lingkungan, semakin berat pula lingkungan tersebut untuk menetralisir air limbah yang sebagian besar dihasilkan dari sisa penggunaan air bersih. Dengan bertambah padatnya jumlah penduduk setiap tahun, maka tingkat aktivitas manusia meningkat dalam usaha untuk meningkatkan taraf hidup dan kesejahteraannya.

Dampak tersebut harus dikelola dengan tepat, khususnya dalam pengelolaan air limbah, oleh karena kenaikan jumlah penduduk akan meningkatkan konsumsi pemakaian air minum/ bersih yang berdampak pada peningkatan jumlah air limbah. Salah satu konsekuensi dari peningkatan jumlah air limbah adalah semakin besarnya volume air limbah domestik yang harus diolah dan dibuang ke badan air. Air limbah, terutama yang mengandung ekskreta manusia dapat mengandung patogen yang berbahaya dan oleh karena itu harus dikelola dan diolah dengan baik. Pengelolaan dan pembuangan air limbah yang tidak memadai dapat menyebabkan kerusakan lingkungan, dan mortalitas.

Proses yang umum dipakai untuk pengolahan air limbah dari keluarga rumah tangga adalah septic tank yang merupakan kombinasi antara proses anaerobik dan peresapan. Proses septic tank adalah proses yang sederhana serta murah dan sesuai untuk daerah kurang padat, apabila dipakai di daerah padat penduduknya akan mengakibatkan pencemaran air bawah tanah. Septic tank biasanya hanya mengolah air limbah dari WC saja. Air limbah lain seperti air limbah cucian, dapur dan kamar mandi langsung dibuang tanpa diolah, sehingga mengakibatkan pencemaran lingkungan. Limbah terbagi atas dua jenis yaitu Grey water (Limbah domestik) dan Black water (Lumpur tinja). Limbah cair domestik adalah hasil buangan dari perumahan, bangunan perdagangan, perkantoran, dan sarana sejenisnya yang dihasikan dari air bekas cucian, air bekas memasak, air bekas mandi, dan sebagainya. Limbah cair adalah air kotor yang membawa sampah dari tempat tinggal, bangunan perdagangan, dan industri berupa campuran air dan bahan padat terlarut atau bahan tersuspensi (Wilgooso, 1979 dalam Safitri, 2009). Air Limbah domestik adalah air yang telah dipergunakan yang berasal dari rumah tangga atau pemukiman termasuk didalamnya air buangan yang berasal dari WC, kamar mandi, tempat cuci, dan tempat memasak. Limbah lumpur tinja ini merupakan buangan dari wc (septic tank). Lumpur tinja ini mengandung mikroba yang paling berbahaya adalah mikroba yaitu bakteri Coli, mikroba yang datang dari tinja tidak baik bagi kesehatan apabila digunakan untuk kepentingan kehidupan manusia terutama kebutuhan rumah tangga.

Salah satu solusi dalam penyediaan prasarana dan sarana air limbah permukiman bagi masyarakat yang tinggal dilingkungan padat penduduk, kumuh dan rawan sanitasi adalah melalui kegiatan Sanitasi Berbasis Masyarakat. Sanitasi adalah usaha kesehatan masyarakat yang menitikberatkan kepada pengawasan terhadap berbagai faktor lingkungan yang mempengaruhi derajat kesehatan manusia, jadi lebih mengutamakan usaha pencegahan terhadap berbagai faktor lingkungan sedemikian rupa munculnya penyakit dapat dihindari. Usaha sanitasi berarti suatu usaha untuk menurunkan jumlah bibit penyakit yang terdapat dalam bahan-bahan pada lingkungan fisik manusia sedemikian rupa sehingga derajat kesehatan manusia dapat terpelihara.

Sanitasi merupakan salah satu pelayanan dasar namun kurang mendapatkan perhatian dan belum menjadi prioritas pembangunan di daerah, dampaknya kondisi sanitasi Indonesia masih relatif buruk dan jauh tertinggal dari sektor-sektor pembangunan lainnya. Hal ini terlihat dari capaian akses sanitasi layak tahun 2013 yang secara nasional baru mencapai 60,91\% (BPS tahun 2013) dimana masih terdapat kesenjangan sebesar $39 \%$ yang harus dipenuhi hingga akhir tahun 
2019 nanti sesuai dengan target pemenuhan universal akses sanitasi sebesar $100 \%$ pada tahun 2019 (Permen PU No. 3, 2015).

Masyarakat di Perumahan Iom merupakan lingkungan yang padat dimana jumlah penduduk terdiri dari $56 \mathrm{KK}$ dengan jumlah 160 orang. Berdasarkan survei awal, di setiap rumah masyarakat di Perumahan Iom Desa Blang Beurangdang sudah memiliki WC. Namun, belum memiliki pengolahan air limbah pada tangki septiktank. Air limbah khususnya limbah yang dihasilkan dari produksi septik tank (black water) dan limbah buangan mandi, cuci dan masak (grey water), hampir semua limbah tersebut tersalurkan ke dalam tangki septik yang langsung dibuang ke selokan tanpa ada pengolahan terlebih dahulu. Kondisi seperti ini sudah berlangsung berlangsung lama sehingga dampak yang dihasilkan yaitu kondisi selokan digenangi oleh banyak limbah yang menyebabkan timbulnya bau dan nyamuk. Selain itu, air buangan limbah yang tidak terkelola dengan baik dapat mencemari tanah dan lingkungan sekitarnya. Berdasarkan permasalahan tersebut, dibutuhkan perencanaan instalasi pengolahan limbah komunal untuk memperbaiki sistem sanitasi di desa ini. Desain IPAL Komunal di Desa Blang Beurandang bertujuan untuk meningkatkan sanitasi masyarakat yang lebih baik dalam mempertahankan stabilitas ekosistem lingkungan. Dengan adanya IPAL Komunal tersebut, maka berbagai limbah dari kamar mandi, dapur dan cucian baju diharapkan lebih aman kandungannya sebelum dibuang ke sungai.

Instalasi Pengolahan Air Limbah (IPAL) adalah Instalasi Pengolahan Air Limbah (IPAL) yang dibangun untuk mengelola air limbah rumah tangga dengan tujuan untuk mencegah pencemaran air tanah dari bakteri Eschercia coli akibat pembuangan limbah rumah tangga yang kurang memadai sehingga tidak menimbulkan dampak terhadap lingkungan atau dapat untuk digunakan pada aktivitas yang lainnya.

Instalasi Pengolahan Air Limbah (IPAL) Komunal merupakan sistem pengolahan air limbah yang dilakukan secara terpusat yaitu terdapat bangunan yang digunakan untuk memproses limbah cair domestik yang difungsikan secara komunal (digunakan oleh sekelompok rumah tangga) agar lebih aman pada saat dibuang ke lingkungan, sesuai dengan baku mutu lingkungan. Limbah cair dari rumah penduduk dialirkan ke bangunan bak tampungan IPAL melalui jaringan pipa.

Sistem ini dilakukan untuk menangani limbah domestik pada wilayah yang tidak memungkinkan untuk dilayani oleh sistem terpusat ataupun secara individual. Penanganan dilakukan pada sebagian wilayah dari suatu kota, dimana setiap rumah tangga yang mempunyai fasilitas MCK pribadi menghubungkan saluran pembuangan ke dalam sistem perpipaan air limbah untuk dialirkan menuju instalasi pengolahan limbah komunal. Untuk sistem yang lebih kecil dapat melayani 2-5 rumah tangga, sedangkan untuk sistem komunal dapat melayani 10-100 rumah tangga atau bahkan dapat lebih. Effluent dari instalasi pengolahan dapat disalurkan menuju sumur resapan atau juga dapat langsung dibuang ke badan air (sungai). Fasilitas sistem komunal dibangun untuk melayani kelompok rumah tangga atau MCK umum. Bangunan pengolahan air limbah ini dapat diterapkan di perkampungan dimana tidak memungkinkan bagi warga masyarakatnya untuk membangun septictank individual di rumahya masing-masing.

Beberapa penelitian terkait permasalahan sanitasi telah dilakukan oleh beberapa peneliti. Untuk menangani permasalahan air limbah domestik masyarakat Pinggir Desa Lingkar Kampus IPB di Kampung Cangkurawok, RT.02/RW.03, Desa Babakan, Kecamatan Dramaga, Kabupaten Bogor yang terdiri dari $70 \mathrm{KK}$ perlu didesain WC komunal dengan dilengkapi tangki septik dan sumur resapan. Desail volume tangki septic adalah $26,5 \mathrm{~m}^{3}$ dengan dimensi panjang sebesar 2,75 $\mathrm{m}$, lebar sebesar $5,5 \mathrm{~m}$ dan tinggi tangki septik sebesar $1,5 \mathrm{~m}$ dan dimensi sumur resapan mempunyai kedalaman $3 \mathrm{~m}$ dan diameter $1 \mathrm{~m}$ [4]. Pelayanan pengolahan air limbah direncanakan secara komunal di Desa Krasak dengan menggunakan dua variabel, yaitu aspek teknis dan aspek kelembagaan. Pada perencanaan pelayanan air limbah komunal Desa Krasak, digunakan pipa PVC tipe $\mathrm{D}$, diameter $114 \mathrm{~mm}$ untuk pipa servis yang menerima air limbah dari setiap rumah. Diameter 
114-140 mm digunakan pada saluran pipa lateral menuju induk yang menuju ke IPAL. Selain itu menggunakan teknologi IPAL berupa ABR dengan luasan lahan dibutuhkan sebesar $32 \mathrm{~m}^{2}$ [3].

\section{METODE PENELITIAN}

Pengumpulan data pada penelitian ini dengan pengumpulan data primer dan data sekunder. Data primer meliputi wawancara dan survei lokasi sebagai lokasi perencanaan IPAL (untuk mendapatkan data karakteristik air limbah Desa Blang Beurandang). Data sekunder meliputi data jumlah penduduk, data jumlah rumah, dan peta topografi wilayah perencanaan. Analisa data meliputi analisis proyeksi jumlah penduduk, debit air limbah, dimensi pipa dan dimensi penentuan bangunan pelengkap IPAL direncanakan setelah data primer dan sekunder diperoleh.

\section{Pengumpulan Data}

Pengumpulan data awal diperlukan untuk dapat mendesain Bangunan IPAL. Data-data yang diperlukan terdiri dari data primer dan data sekunder. Data primer adalah data yang diambil secara langsung pada wilayah perencanaan dengan melakukan observasi untuk mengetahui kondisi di lapangan. Data primer yang diambil berupa foto kondisi pembuangan limbah di lokasi perencanaan, foto eksisting lahan perencanaan IPAL, dan wawancara terhadap masyarakat setempat. Wawancara dilakukan untuk mengetahui ada atau tidaknya WC di rumah mereka, jumlah anggota keluarga, dan jenis pekerjaan. Data sekunder yang digunakan adalah data jumlah penduduk, data jumlah rumah di Desa Blang Beurandange, peta wilayah perencanaan, dan peta topografi wilayah perencanaan. Data-data tersebut akan digunakan dalam perencanaan pelayanan air limbah komunal di Desa Blang Beurandang.

\section{Analisis Data}

Perencanaan IPAL Komunal antara lain :

a. Perhitungan proyeksi jumlah penduduk

Perhitungan proyeksi jumlah penduduk untuk 10 tahun ke depan dengan data yang diambil adalah jumlah penduduk mulai dari tahun 2013-2017. Jumlah penduduk pada suatu daerah merupakan salah satu hal yang penting dalam perhitungan sistem penyaluran air limbah. Semakin banyak penduduk maka semakin besar air limbah yang dihasilkan.

Proyeksi jumlah penduduk dengan metode geometrik menggunakan Persamaan sebagai berikut.

$\operatorname{Pn}=\operatorname{Po}(1+q)^{\mathrm{n}}$

dengan $\mathrm{Pn}=$ jumlah penduduk tahun rencana, $\mathrm{Po}=$ jumlah penduduk tahun awal, $\mathrm{n}=$ jumlah tahun rencana, dan $\mathrm{q}=$ laju pertumbuhan penduduk.

\section{b. Perhitungan debit air limbah}

Berdasarkan Kriteria Perencanaan Ditjen Cipta Karya Dinas PU (1996), kebutuhan air bersih per orang per hari diambil berdasarkan jumlah penduduk. Apabila dibawah 20.000 jiwa, maka kebutuhan air bersih diambil 80lt/org/hari. Perhitungan debit air limbah dilakukan menggunakan asumsi bahwa $80 \%$ dari kebutuhan air minum akan menjadi air limbah. 
Vol. 4 No.1 April 2018

pp. $110-120$

Tabel 1. Kriteria Perencanaan Air Bersih dan Standar Kebutuhan Air Domestik

\begin{tabular}{|c|c|c|c|c|c|c|}
\hline \multirow{3}{*}{ No } & \multirow{3}{*}{ URAIAN / KRITERIA } & \multicolumn{5}{|c|}{ KATEGORI KOTA BERDASARKAN } \\
\hline & & $>1.000 .000$ & $\begin{array}{c}500.000 \\
\mathrm{~s} / \mathrm{d} \\
1.000 .000\end{array}$ & $\begin{array}{l}100.000 \\
\text { s/d } \\
500.000\end{array}$ & $\begin{array}{c}20.000 \\
\mathrm{~s} / \mathrm{d} \\
100.000\end{array}$ & $<20.000$ \\
\hline & & $\begin{array}{c}\text { Kota } \\
\text { Metropolitan }\end{array}$ & $\begin{array}{l}\text { Kota } \\
\text { Besar }\end{array}$ & $\begin{array}{c}\text { Kota } \\
\text { Sedang }\end{array}$ & $\begin{array}{l}\text { Kota } \\
\text { Kecil }\end{array}$ & Desa \\
\hline 1 & $\begin{array}{l}\text { Konsumsi Unit } \\
\text { Sambungan } \\
\text { Rumah (SR) (ltr/org/hari) }\end{array}$ & $>150$ & $150-120$ & $90-120$ & $80-120$ & $60-80$ \\
\hline 2 & $\begin{array}{l}\text { Konsumsi Unit Hidran } \\
\text { Umum } \\
\text { (HU) (ltr/org/hari) }\end{array}$ & $20-40$ & $20-40$ & $20-40$ & $20-40$ & $20-40$ \\
\hline 3 & Faktor hari maksimum & $\begin{array}{l}1.15-1.25 \\
* \text { harian }\end{array}$ & $\begin{array}{l}1.15-1.25 \\
* \text { harian }\end{array}$ & $\begin{array}{c}1.15- \\
1.25 \\
* \text { harian }\end{array}$ & $\begin{array}{l}1.15- \\
1.25 \\
* \text { harian }\end{array}$ & $\begin{array}{l}1.15-1.25 \\
* \text { harian }\end{array}$ \\
\hline 4 & Faktor jam puncak & $\begin{array}{l}1.75-2.0 \\
* \text { hari maks }\end{array}$ & $\begin{array}{c}1.75-2.0 \\
* \text { hari } \\
\text { maks } \\
\end{array}$ & $\begin{array}{c}1.75-2.0 \\
* \text { hari } \\
\text { maks } \\
\end{array}$ & $\begin{array}{c}1.75-2.0 \\
* \text { hari } \\
\text { maks } \\
\end{array}$ & $\begin{array}{l}1.75-2.0 \\
* \text { hari maks }\end{array}$ \\
\hline 5 & Jumlah jiwa per SR (Jiwa) & 5 & 5 & 5 & 5 & 5 \\
\hline 6 & $\begin{array}{l}\text { Jumlah jiwa per HU } \\
\text { (Jiwa) }\end{array}$ & 100 & 100 & 100 & $100-200$ & 200 \\
\hline 7 & $\begin{array}{l}\text { Sisa tekan di penyediaan } \\
\text { distribusi (meter) }\end{array}$ & 10 & 10 & 10 & 10 & 10 \\
\hline 8 & Jam operasi (jam) & 24 & 24 & 24 & 24 & 24 \\
\hline 9 & $\begin{array}{l}\text { Volume reservoir } \\
\text { (\% max day demand })\end{array}$ & $15-25$ & $15-25$ & $15-25$ & $15-25$ & $15-25$ \\
\hline 10 & SR : HU & $\begin{array}{c}50: 50 \\
\text { s/d } \\
80: 20\end{array}$ & $\begin{array}{c}50: 50 \\
\text { s/d } \\
80: 20\end{array}$ & $80: 20$ & $70: 30$ & $70: 30$ \\
\hline
\end{tabular}

Sumber : Kriteria Perencanaan Ditjen Cipta Karya Dinas PU, 1996

Perhitungan ini dilakukan untuk mengetahui berapa besar debit dan beban air limbah yang masuk ke badan air penerima. Perhitungan beban air limbah yang masuk ke badan air penerima dilakukan dengan menggunakan karakteristik air limbah. Debit Rata-Rata Air Limbah dapat dihitung dengan menggunakan rumus :

$\mathrm{Q}_{\text {rata-rata air limbah }}=(80) \% \times \mathrm{Q}_{\text {air minum }}$

dengan $\mathrm{Q}_{\text {air minum }}=80$ liter/ orang/ hari

Timbulan air limbah domestik (Q) dapat menggunakan rumus :

$\mathrm{Q}_{\text {air limbah }}=1,1 \times \mathrm{Q}_{\text {rata-rata air limbah }}$

c. Perencanaan sistem jaringan perpipaan

Jaringan pipa sambungan rumah dapat ditentukan berdasarkan jenis buangan air limbah. Pipa dari kloset (black water) : diameter pipa minimal $75 \mathrm{~mm}$, bahan dari PVC, kemiringan pipa (1-2)\%. Pipa untuk pengaliran air limbah non tinja (grey water) : Diameter pipa minimal $50 \mathrm{~mm}$, bahan dari 
PVC, kemiringan $(0,5-1) \%$, khusus air limbah dari dapur harus dilengkapi dengan unit perangkap lemak (grease trap). Pada pipa sekunder slope yang direncanakan berkisar $(0,7-1) \%$, sedangkan pipa induk (pipa primer) direncanakan slope $(0,5-0,7) \%$.

d. Perencanaan bangunan IPAL yang meliputi bak pengendap, bak AF, dan bak ABR Kapasitas IPAL yang direncanakan yaitu menggunakan Persamaan :

Kapasitas IPAL $=Q_{\text {air limbah }} \mathrm{X}$ Pn

Desain bak ekualisasi (Inlet), bak Settler/Pengendap, bak Anaerobic Buffle Reactor (ABR), bak Anaerobic Filter (AF), bak pengendap akhir (outlet) menggunakan Persamaan 5.

Volume $=\frac{H R T}{24} x$ KapasitasI $P A L$

dengan HRT = waktu tinggal limbah dalam bak, HRT bak ekualisasi $=30$ menit, HRT Bak Settler $=12 \mathrm{jam}, \mathrm{HRT}$ bak $\mathrm{ABR}=6 \mathrm{jam}$, dan HRT bak AF $=18 \mathrm{jam}$, HRT bak outlet $=30$ menit.

e. Menentukan diameter pipa

Menentukan diameter pipa dari kloset (black water) sesuai dengan standar teknis. Menentukan diameter pipa untuk pengaliran air limbah non tinja (grey water) sesuai dengan standar teknis.

f. Membuat rencana jalur pipa

Membuat rencana jalur pipa dari sambungan tiap-tiap rumah diperukan agar dapat menangkap titik kegiatan yang menghasilkan air limbah (kloset, Mandi, dapur, dan cucian lainnya) serta menentukan letak manhole dan bak kontrol.

g. Menghitung desain konstruksi IPAL

Menghitung desain konstruksi IPAL untuk mendapatkan dimensi bak pemisah lemak, bak ekualisasi, bak pengendapan awal (settler), reaktor boifilter anaerob dan bak pengendapan akhir, serta kapasitas IPAL biofilter dapat dihitung menggunakan rumus (3), (4), (5).

h. Hasil desain

Setelah data selesai dianalisis dan dilakukan perhitungan, maka untuk membuat gambar hasil desain IPAL komunal digambar menggunakan software Autocad.

\section{Penentuan Lokasi IPAL}

Ada dua kriteria untuk syarat-syarat penentuan lokasi IPAL, yaitu kriteria Teknik dan Nonteknis (Kementerian Pekerjaan Umum dan Perumahan Rakyat, 2017).

1. Kriteria Teknis

a) Jarak

Jarak minimum antara IPAL dengan pusat kota dan pemukiman adalah $3 \mathrm{Km}$.

b) Topografi lahan

- Kemiringan tanah

Kemiringan tanah yang dinilai lebih baik jika mempunyai kemiringan $2 \%$.

- Elevasi tanah

Sistem pendistribusian IPAL dinilai baik jika perumahan terletak lebih tinggi dari letak IPALnya (elevasi tanah yang baik apabila sistem distribusinya bisa dialirkan secara gravitasi).

c) Badan air penerima

- Yang dimaksud dengan badan air penerima adalah sungai. 
- Sungai yang dibagi menjadi beberapa kelas yaitu kelas I hingga kelas IV. Semakin bagus kualitas sungai semakin tinggi kelasnya, sehingga apabila ingin membuang air hasil olahan IPAL perlu memperhatikan kelas sungainya.

Jika air hasil olahan IPAL akan dibuang ke sungai kelas I, maka efisiensi IPAL perlu ditingkatkan agar air hasil olahannya mampu memenuhi baku mutu sungai kelas I. Jadi badan air penerima berperan sebagai penentu besarnya kualitas effluent yang harus dicapai oleh IPAL.

d) Bahaya banjir

- $\quad$ Lokasi IPAL yang dipilih pada lokasi yang bebas akan banjir.

e) Jenis tanah

Pilihan terbaik untuk lokasi IPAL adalah tanah dengan jenis yang kedap air seperti tanah lempung.

2. Kriteria Non-Teknis

a) Legalitas lahan

- Kepemilikan tanah, merupakan lahan yang tidak bermasalah. Pilihan yang dinilai lebih baik adalah lahan lirik pemerintah.

- Kesuaian RUTR/RTRW.

- Dukungan masyarakat.

b) Batas administrasi

Terletak pada batas administrasi kota yang berkepentingan.

c) Tata guna lahan

Pilihan yang terbaik jika merupakan lahan tidak produktif.

\section{Sistem Jaringan Perpipaan}

Jaringan Pipa Sambungan Rumah

Jaringan pipa sambungan rumah dapat ditentukan berdasarkan :

- Pipa dari kloset (black water) : Diameter pipa minimal $75 \mathrm{~mm}$, bahan dari PVC, asbes semen, kemiringan pipa (1-3)\%, dan dilengkapi dengan unit pengendap kotoran (manhole).

- Pipa untuk pengaliran air limbah non tinja (grey water) : Diameter pipa minimal 50 mm, bahan dari PVC atau asbes semen, kemiringan (0,5-1) \%, khusus air limbah dari dapur harus dilengkapi dengan unit perangkap lemak (grease trap).

\section{HASIL DAN PEMBAHASAN}

Beberapa desa di Kabupaten Aceh Barat yang termasuk daerah rawan sanitasi meliputi Gampong Ujong Kalak, Gampong Blang Berandang, Gampong Ujong Baroh, Gampong Panggong serta Gampong Kampung Belakang.Dari survey yang dilakukan di Gampong Blang Berandang, banyak dijumpai beragam permasalahan dalam pengelolaan air limbah khususnya limbah yang dihasilkan dari produksi Saptick tank dan limbah buangan mandi, cuci dan masak. Hampir semua limbah buangan tinja masyarakat tersalurkan ke dalam tangki saptik yang menampung limbah padat tinja dengan limbah cair langsung dibuang ke selokan tanpa ada pengolahan terlebih dahulu. Untuk limbah grey water langsung dibuang ke selokan. Kondisi seperti ini sudah berlangsung lama sehingga dampak yang dihasilkan yaitu kondisi selokan buangan yang sudah tersumbat oleh sampah ditambah lagi dengan kondisi buangan limbah black water yang belum dikelola langsung 
Vol. 4 No.1 April 2018

pp. $110-120$

dibuang ke selokan warga. Selain itu, grey water ada yang dibuang langsung ke saaluran irigasi yang menuju ke sawah.

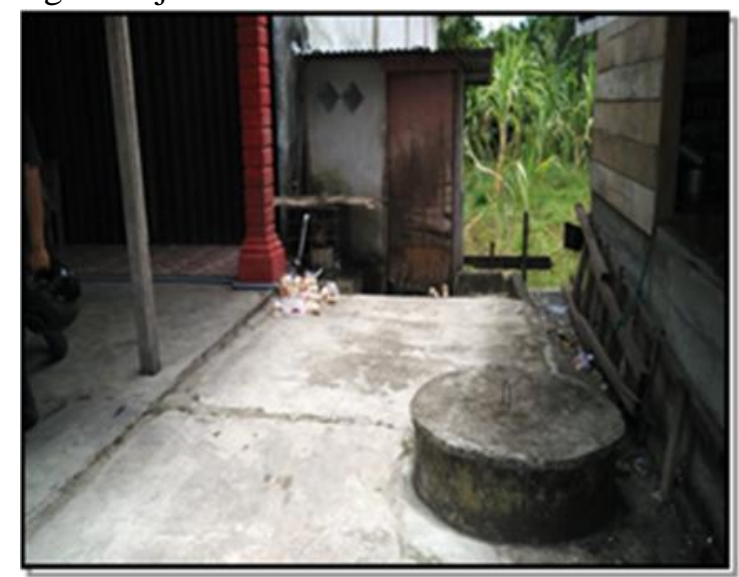

Gambar 1. Kondisi tidak sehat dimana WC berada dekat dengan Sumur.

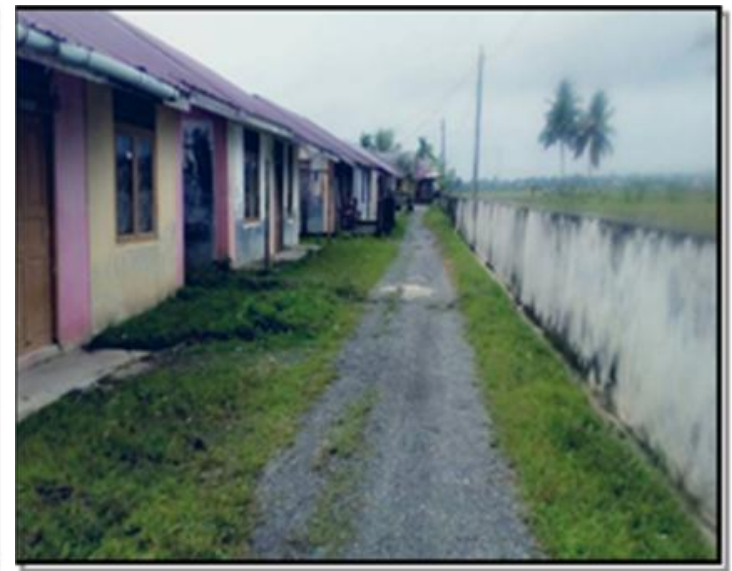

Gambar 2. Kondisi tidak sehat dimana buangan grey water langsung ke saluran irigasi.

Hasil proyeksi penduduk dari metode geometrik diperoleh jumlah penduduk untuk 10 tahun ke depan adalah 326 orang. Data-data yang digunakan untuk perhitungan dimensi bangunan IPAL sebagai berikut.

$\mathrm{Pn}=326$ orang

$\mathrm{Q}_{\text {air bersih }}=80 \mathrm{lt} / \mathrm{orang} / \mathrm{hari}$

Kapasitas air limbah $=20.872$ liter $/$ hari $=0,942 \mathrm{~m}^{3} / \mathrm{jam}$

IPAL Komunal mengolah air limbah dari rumah-rumah melalui jaringan perpipaan. Pipa yang dipergunakan adalah pipa jenis air limbah berbahan PVC SNI dengan diameter $4-6$ inchi (ditanam sesuai dengan peraturan dari SNI yang berlaku) dan dilengkapi dengan bangunan pelengkap (bak kontrol, bak perangkap minyak, dan manhole) di setiap ujung gang, belokan dan persimpangan. Hasil desain diperoleh dimensi Bangunan IPAL direncanakan memiliki panjang 11 $\mathrm{m}$ dan lebar bangunan 3.25 meter.Pada desain IPAL Komunal di Desa Blang Beurandange ini, jenis pipa yang digunakan adalah tipe PVC dan tipe PVC SDR-41. Pipa dengan diameter 3" tipe PVC diperuntukkan pada pipa yang mengalirkan buangan limbah dari jamban ke bak kontrol, sedangkan pipa dengan diameter 4" tipe PVC SDR-41 diperuntukkan untuk mengalirkan limbah dari bak kontrol menuju pipa induk, dan pipa dengan diameter 6" tipe PVC SDR-41 diperuntukkan untuk mengalirkan limbah dari pipa induk menuju bangunan IPAL. Sistem IPAL yang digunakan adalah IPAL Anaerob sebab untuk biaya investasi dan biaya operasional IPAL Anaerob termasuk katagori murah dan pelaksanaan perawatan bangunannya lebih mudah dibandingkan dengan sistem yang lain. Panjang pipa diameter 6" yang dibutuhkan adalah $108 \mathrm{~m}$, pipa diameter 4" dibutuhkan sepanjang $258 \mathrm{~m}$, dan pipa diameter 3" dibutuhkan sepanjang $390 \mathrm{~m}$. Dari analisis data diperoleh, jumlah tutup mainhole di Bangunan IPAL ada 16 buah. Sedangkan Mainhole di jaringan perpipaan tutupnya menggunakan coran beton sebanyak 24 buah terdiri dari 18 buah dengan ukuran 40x40 $\mathrm{cm}$ dan 6 buah dengan diameter $60 \times 60 \mathrm{~cm}$.

Desain dimensi Bangunan IPAL direncanakan memiliki panjang $11 \mathrm{~m}$ dan lebar bangunan 3.25 meter. Bangunan ini tediri dari beberapa ruang di antaranya bak inlet dengan dimensi panjang 1.15 $\mathrm{m}$ danlebar $3.25 \mathrm{~m}$, bak settler (bak pengendap) dengan panjang 4,00 $\mathrm{m}$ dan lebar 3,25 m, bak pembagi dengan panjang $0,80 \mathrm{~m}$ dan lebar $3,25 \mathrm{~m}$, bak filter (bak media filter) dengan panjang $1 \mathrm{~m}$ dan lebar $1 \mathrm{~m}$ sebanyak 12 buah dan bak keluar (outlet) dengan panjang $1 \mathrm{~m}$ dan lebar $1 \mathrm{~m}$. Pada bak filter digunakan biofilter dengan tujuan untuk menumbuhkan bakteri dengan sistem anaerob. 
Vol. 4 No.1 April 2018

pp. $110-120$

Biofilter biasanya digunakan yang fabrikasi. Namun pada desain IPAL ini digunakan biofilter dari bahan botol plastik bekas yang didaur ulang dengan tujuan untuk mengurangi sampah dan juga untuk menghemat biaya pengeluaran pembangunan.Luas daerah layanan yang diperuntukkan untuk desain adalah 16,8 ha. Untuk desain IPAL, lahan yang diperlukan seluas 29,6 $\mathrm{m}^{2}$. Bangunanbangunan yang terdapat pada IPAL Komunal disajikan pada Gambar 3 dan Gambar potongan tampak samping bangunan-bangunan yang terdapat pada IPAL Komunal disajikan pada Gambar 4.
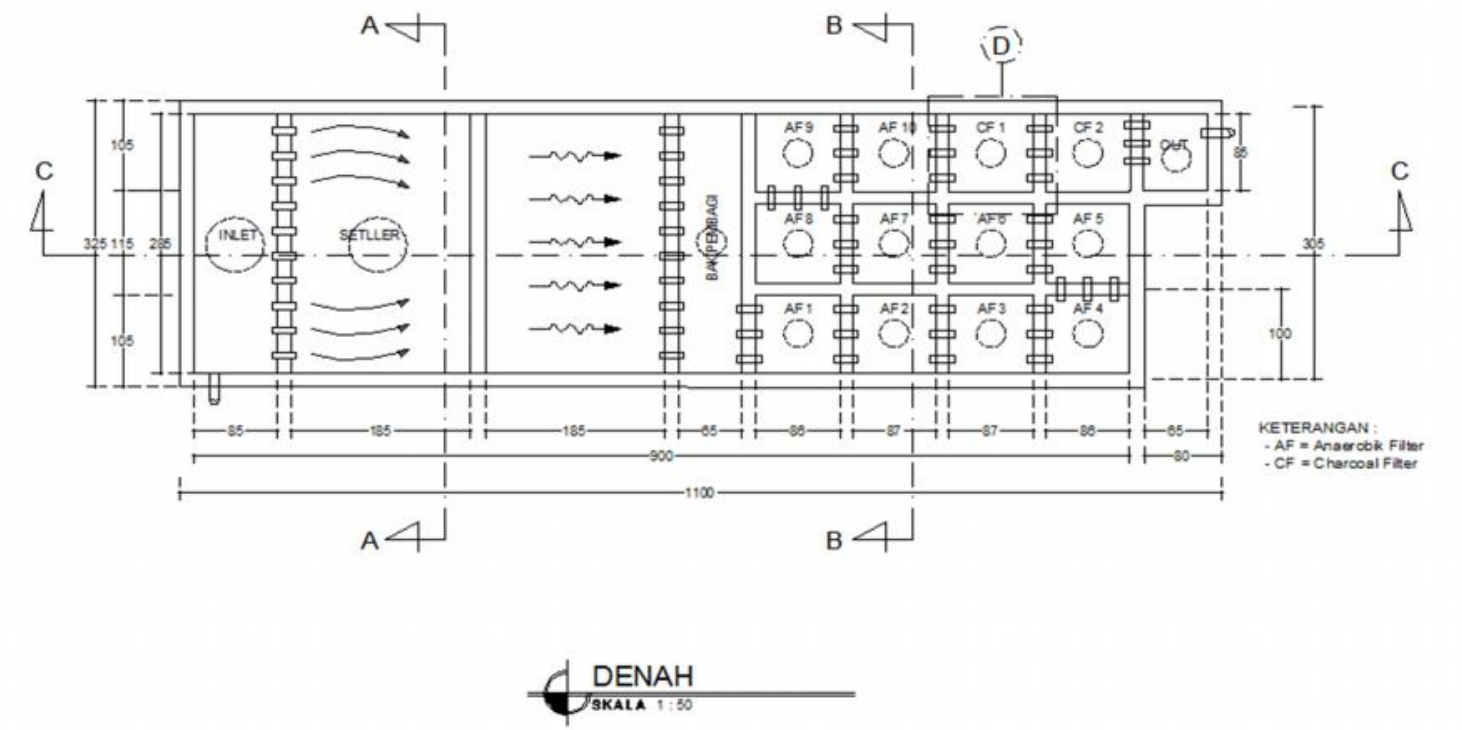

Gambar 3. Bangunan-bangunan yang ada pada IPAL

Sumber : Hasil Desain

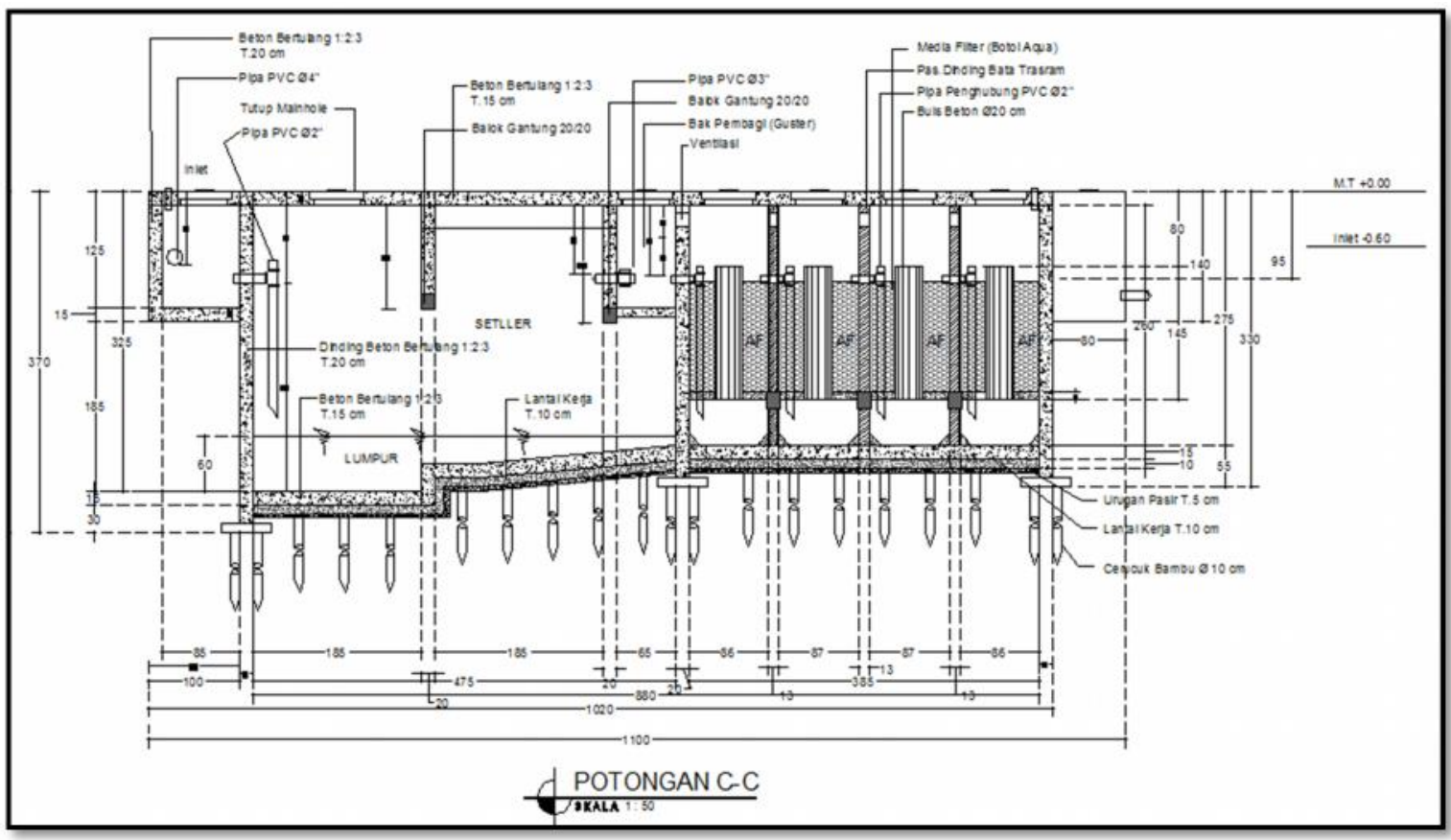

Gambar 4. Tampak Samping Bangunan-bangunan yang ada pada IPAL

Sumber : Hasil Desain 
Vol. 4 No.1 April 2018

pp. $110-120$

Tabel 1. Rekapitulasi dimensi bangunan IPAL

\begin{tabular}{|clcccc|}
\hline \multirow{2}{*}{ No } & \multirow{2}{*}{ Nama Bak } & \multirow{2}{*}{ Volume yang diperlukan $\left(\mathrm{m}^{3}\right)$} & \multicolumn{3}{c|}{ Dimensi Bak } \\
\cline { 4 - 6 } & & & $\mathrm{P}(\mathrm{m})$ & $\mathrm{L}(\mathrm{m})$ & $\mathrm{T}(\mathrm{m})$ \\
\hline 1 & Bak Ekualisasi (inlet) & 0,7764 & 1,15 & 3,25 & 1,5 \\
\hline 2 & Bak Settler & 17,2115 & 4 & 3,25 & 3 \\
\hline 3 & Bak ABR & 7,994 & 0,8 & 3,25 & 3 \\
\hline 4 & Bak AF & 11,6570 & 1 & 1 & 1,5 \\
\hline 5 & Bak akhir (outlet) & 0,7425 & 1 & 1 & 1 \\
\hline
\end{tabular}

Beberapa bangunan yang terdapat pada IPAL Komunal dengan sistem Anaerob

1. Bak Ekualisasi (Inlet)

Dimensi bak inlet yang direncanakan yaitu $1,15 \mathrm{~m}$ x 3,25 m dengan kedalaman 1,5 m. Bagian inlet ini berfungsi untuk jalan masuk pertama limbah tinja dan limbah dapur serta kamar mandi. Dimana fungsi bak inlet juga untuk membagi aliran yang masuk agar tijak terjadi turbulen pada saat jam-jam tertentu. Sehingga berubah menjadi laminer dengan adanya bak inlet ini.

\section{Settler (Bak Pengendap)}

Dimensi bak settler yang direncanakan adalah $4 \mathrm{~m} \mathrm{x} \mathrm{3,25} \mathrm{m} \mathrm{dengan} \mathrm{kedalaman} 3 \mathrm{~m}$ (sudah ditambah dengan ambang bebas). Bangunan ini sama dengan settling tank/septic tank dimana didalamnya terjadi proses sedimentasi/pengendapan dan dilanjutkan dengan stabilisasi dari bahan yang diendapkan tersebut melalui proses anaerobic. Tujuannya adalah untuk mengendapkan dan menstabilkan lumpur aktif sebelum masuk ke pengolahan selanjutnya (sebagai pengolahan awal).

\section{Anaerobic Buffle Reactor (ABR)}

Unit proses pengolahan air limbah yang digunakan pada perencanaan ini berupa Anaerobic Baffled Reactor yang dipilih karena murah dalam operasional dan perawatannya serta memiliki efisiensi yang cukup tinggi. Dimensi bak ABR yang direncanakan adalah 0,8 $\mathrm{m}$ x 3,25 m dengan kedalaman $3 \mathrm{~m}$ (sudah ditambah dengan ambang bebas) dan bangunan ABR ini direncanakan 2 buah. Bangunan ini bertujuan untuk mengalirkan air limbah dimana terjadi proses pengendapan selanjutnya melewati/mengkontakan dengan lumpur aktif dan terjadi proses penguraian karena kontak antara limbah dengan akumulasi mikroorganisme pada lumpur aktif.

\section{Anaerobic Filter (AF)}

Dimensi bak settler yang direncanakan adalah $1 \mathrm{~m} \mathrm{x} 1 \mathrm{~m}$ dengan kedalaman $1,5 \mathrm{~m}$ (sudah ditambah dengan ambang bebas) dan bangunan AF ini direncanakan sebanyak 12 buah. Bangunan ini menggunakan sistem yang diharapkan untuk memproses bahan-bahan yang tidak terendapkan dan bahan padat terlarut (dissolved solid) secara mengkontakan dengan surplus mikro organisme pada media filter dimana akan menguraian bahan organik terlarut (dissolved organic) dan bahan organic yang terspresi (dispersed organic) yang ada dalam limbah.

Aliran dari Bak ABR akan menuju ke dalam BAK AF dimana bak AF merupakan bak yang terdapat media filter yang berguna sebagai tempat hidup bakteri. Bakteri yang terdapat pada air limbah pada saat masuk ke dalam bak AF akan menempel pada media ini, sehingga air limbah menjadi berkurang bakterinya. Media filter direncanakan berasal dari bioball sarang tawon dari pabrikasi atau menggunakan botol bekas air mineral. Proses didalam bak ini berlangsung secara alami dengan durasi yang telah didesain dari awal, sehingga didapat air hasil keluaran dari bak AF (effluent) sudah dapat dibuang ke badan air sesuai dengan permen LHK 2016 tentang baku mutu air limbah domestik. 
5. Bak Outlet

Bak ini berfungsi sebagai hasil akhir (Effluent) dari pengolahan dari sebelumnya, dimana air hasil dari bagian outlet inilah yang akan rutin di test di laboratorium mengetahui kadar BOD, COD, Nitrogen dan lain sebagainya. Dimensi bak outlet yang direncanakan yaitu $1 \mathrm{~m}$ x $1 \mathrm{~m}$ dengan kedalaman $1 \mathrm{~m}$.

\section{KESIMPULAN}

Perencanaan IPAL Komunal di Desa Blang Beurandang, Kecamatan Johan Pahlawan, Kabupaten Aceh Barat diperuntukkan untuk mengatasi permasalahan sanitasi di desa tersebut. Luas area lahan yang diperlukan dalam perencanaan IPAL adalah $29,6 \mathrm{~m}^{2}$ dengan luas daerah layanan 16,8 ha dimana yang termasuk luas daerah layanan ini yaitu Perumahan Iom di Dusun Paya Silimeng. Bangunan yang terdapat pada IPAL Komunal dengan sistem Anaerob diantaranya Bak Ekualisasi (Inlet), Settler (Bak Pengendap), bak Anaerobic Buffle Reactor (ABR), bak Anaerobic Filter (AF), dan bak outlet. Hasil desain diperoleh dimensi Bangunan IPAL direncanakan memiliki panjang 11 $\mathrm{m}$ dan lebar bangunan 3.25 meter. Bangunan ini tediri dari beberapa ruang di antaranya bak inlet dengan dimensi panjang $1.15 \mathrm{~m}$ dan lebar $3.25 \mathrm{~m}$, bak settler (bak pengendap) dengan panjang 4,00 $\mathrm{m}$ dan lebar 3,25 m, bak pembagi dengan panjang $0,80 \mathrm{~m}$ dan lebar 3,25 m, bak filter (bak media filter) dengan panjang $1 \mathrm{~m}$ dan lebar $1 \mathrm{~m}$ sebanyak 12 buah dan bak keluar (outlet) dengan panjang $1 \mathrm{~m}$ dan lebar $1 \mathrm{~m}$.

\section{DAFTAR PUSTAKA}

[1] Daryanto, 2004, Masalah Pencemaran, Bandung, Tarsito.

[2] Kementerian Pekerjaan Umum dan Perumahan Rakyat, 2017, Perencanaan IPAL Komunal Berbasis Sanitasi, Jakarta.

[3] Prameswari, RA. and Purnomo, A. Perencanaan Pelayanan Air Limbah Komunal di Desa Krasak Kecamatan Jatibarang Kota Indramayu, 2014. Jurnal Teknik POMITS, vol. 3, no. 2. p. 81-84.

[4] Sapel, A., Purwanto, MY., dan Kurniawan, A. 2011, Desain Instalasi Pengolah Limbah WC Komunal Masyarakat Pinggir Sungai Desa Lingkar Kampus. Jurnal Ilmu Pertanian Indonesia, vol 16, no. 2, p. 91-99. 